\title{
LEFT VENTRICULAR DYSFUNCTION AFTER OPEN REPAIR OF SIMPLE CONGENITAL HEART DEFECTS IN INFANTS AND CHILDREN: QUANTITATION WITH THE USE OF A CONDUCTANCE CATHETER IMMEDIATELY AFTER BYPASS
}

Rajiv R. Chaturvedi, MRCP ${ }^{\mathrm{a}}$ Christopher Lincoln, FRCS ${ }^{\mathrm{b}}$ John W. W. Gothard, FRCA ${ }^{\mathrm{c}}$ Michael H. Scallan, FRCA ${ }^{\mathrm{c}}$

Paul A. White, MSc ${ }^{\mathrm{a}}$

Andrew N. Redington, MD, FRCP ${ }^{\mathrm{a}}$ Darryl F. Shore, FRCS ${ }^{\mathrm{b}}$
Objective: Quantification of myocardial injury after the simplest pediatric operations by load-independent indices of left ventricular function, using conductance and Mikro-Tip pressure catheters (Millar Instruments, Inc., Houston, Tex.) inserted through the left ventricular apex. Methods: Sixteen infants and children with intact ventricular septum undergoing cardiac operations had left ventricular function measured, immediately before and after bypass. Real-time pressure-volume loops were generated by conductance and Mikro-Tip pressure catheters placed in the long-axis via the left ventricular apex, and preload was varied by transient snaring of the inferior vena cava. Results: Good quality pressure-volume loops were generated in 13 patients (atrial septal defects, $n=11$; double-chambered right ventricle, $n=1$; supravalvular aortic stenosis, $n=1$; age 0.25 to 14.4 years, weight 3.1 to $46.4 \mathrm{~kg}$ ). Their mean bypass time was $41 \pm 14$ minutes and mean aortic crossclamp time $27 \pm 11$ minutes. End-systolic elastance decreased by $40.7 \%$ from $0.34 \pm 0.17$ to $0.21 \pm 0.15 \mathrm{~mm} \mathrm{Hg} \mathbf{H g}^{-1} \cdot \mathrm{ml}^{-1} \cdot \mathrm{kg}^{-1}$ $(p<0.001)$. There were no significant changes in the slope of the stroke work-end-diastolic volume relationship, end-diastolic elastance, time constant of isovolumic relaxation, and normalized values of the maxima and minima of the first derivative of developed left ventricular pressure. Conclusion: Load-independent indices of left ventricular function can be derived from left ventricular pressure-volume loops generated by conductance and Mikro-Tip pressure catheters during the perioperative period in infants and children undergoing cardiac operations. Incomplete myocardial protection was demonstrated by a deterioration in systolic function after even short bypass and crossclamp times. (J Thorac Cardiovasc Surg 1998;115:77-83) gnorance of the cause of postoperative myocardial dysfunction in the immature heart is compounded by the incomplete myocardial protection afforded by

From the Departments of Paediatric Cardiology, ${ }^{a}$ Cardiac Surgery, ${ }^{\mathrm{b}}$ and Anaesthesia, ${ }^{\mathrm{c}}$ Royal Brompton Hospital, Imperial College of Science, Technology, and Medicine, London, United Kingdom.

This research was funded by the Scott Rhodes Research Fund and the Royal Brompton Hospital Clinical Research Committee.

Received for publication Oct. 23, 1996; revisions requested March 3, 1997; revisions received May 5, 1997; accepted for publication June 12, 1997.

Address for reprints: Andrew N. Redington, MD, FRCP, Royal Brompton Hospital, Sydney Street, Chelsea, London SW3 6NP, United Kingdom.

Copyright (C) 1998 by Mosby, Inc.

$0022-5223 / 98 \$ 5.00+0 \quad \mathbf{1 2 / 1 / 8 4 3 0 5}$ current cardioplegic strategies. ${ }^{1-5}$ Investigations of the mechanisms and treatment of postoperative ventricular dysfunction are hampered by use of nonspecific clinical end points as indirect estimates of ventricular function, for example, requirement for inotropic agents, duration of ventilation, intensive care unit stay, and mortality. These clinical indices are relatively insensitive to changes in ventricular function and necessitate large cohorts of patients to detect even major differences in outcome from differing myocardial protective strategies.

To measure left ventricular function optimally during the perioperative period, with its dramatic changes in loading conditions, necessitates the use of load-independent indices of systolic and diastolic function. In infants and children with an intact ventricular septum undergoing cardiac operations (mainly atrial septal defect closure), we report the 
Table I. Patient characteristics

\begin{tabular}{cclccc}
\hline Patient & $\begin{array}{c}\text { Age } \\
(y r)\end{array}$ & \multicolumn{1}{c}{ Diagnosis } & $\begin{array}{c}\text { Bypass } \\
\text { duration }(\text { min })\end{array}$ & $\begin{array}{c}\text { Crossclamp } \\
\text { duration (min) }\end{array}$ & Cardioplegia \\
\hline $1^{*}$ & 0.2 & Primum ASD & 62 & 31 & Blood \\
2 & 1.3 & Primum ASD & 59 & 48 & Blood \\
3 & 3.2 & Secundum ASD & 49 & 34 & Crystalloid \\
4 & 4.1 & Double-chambered RV & 40 & 23 & Crystalloid \\
5 & 4.4 & Secundum ASD & 33 & 17 & Crystalloid \\
6 & 5.1 & Secundum ASD & 30 & 20 & Blood \\
7 & 5.1 & Secundum ASD & 35 & 25 & Blood \\
8 & 5.2 & Primum ASD & 33 & 24 & Crystalloid \\
9 & 6.6 & Primum ASD & 69 & 48 & Blood \\
10 & 7.4 & Secundum ASD & 26 & 15 & Crystalloid \\
11 & 7.5 & Supravalvular AS & 40 & 26 & Blood \\
12 & 12.1 & Secundum ASD & 32 & 20 & Crystalloid \\
13 & 14.4 & Secundum ASD & 29 & 23 & Crystalloid
\end{tabular}

$A S D$, Atrial septal defect; $R V$, right ventricle; $A S$, aortic stenosis.

*Patient 1 died as a result of a hypoplastic lung and pulmonary hypertension.

changes in left ventricular function assessed from the pressure-volume plane with the use of a conductance catheter and Mikro-Tip pressure catheter (Millar Instruments, Inc., Houston, Tex). In animal and human studies the conductance catheter is placed in the long axis of the left ventricle, most commonly through the aortic valve, with the use of retrograde arterial cannulation or aortotomy. ${ }^{6-11}$ This is clearly impractical in children undergoing bypass procedures, and in this study we report the first clinical use of custom-built miniature catheters placed in the same long axis, but via the left ventricular apex.

\section{Methods}

Patients. Study design and consent forms were approved by the Royal Brompton Hospital Ethics Committee. Informed consent was obtained for 16 consecutive children with intact ventricular septum undergoing cardiac operations. Patients with primum atrial septal defect did not have left heart inflow obstruction and had no more than trivial left atrioventricular valve regurgitation on echocardiography. In three patients technically adequate recordings could not be obtained, and they were excluded from further analysis. Characteristics of the 13 children used for data analysis are given in Table I.

Cardiopulmonary bypass and myocardial protection. All patients received a standardized anesthetic protocol: induction with isoflurane gas and maintenance with pancuronium, fentanyl, and isoflurane. They underwent bicaval and ascending aorta cannulation, and subsequently core cooling was begun during bypass to $25^{\circ}$ to $28^{\circ} \mathrm{C}$. Each patient was prospectively randomized to receive either blood cardioplegic or cold crystalloid cardioplegic solution (St. Thomas' Hospital solution 1, $20 \mathrm{ml} / \mathrm{kg}$ ) delivered by the perfusionist into the aortic root at $40 \mathrm{~mm}$ $\mathrm{Hg}$, after aortic crossclamping. The blood cardioplegic solution was a nondiluted, high-hematocrit solution with a
$20 \mathrm{mmol} / \mathrm{L}$ concentration of potassium and a $0.4 \mathrm{mmol} / \mathrm{L}$ concentration of magnesium. Arrest was induced by warm blood and maintained with cold blood $\left(5^{\circ}\right.$ to $\left.8^{\circ} \mathrm{C}\right)$. Cardiopulmonary bypass flow was $150 \mathrm{ml} / \mathrm{kg}$ per minute (weight $<10 \mathrm{~kg}$ ) or $2.4 \mathrm{~L} / \mathrm{m}^{2}$ per minute (weight $>10 \mathrm{~kg}$ ). Hemodilution was to a hemoglobin concentration of 8 to $9 \mathrm{gm} / \mathrm{dl}$. At the end of the procedure the crossclamp was removed and rewarming begun on bypass. The mean postbypass hemoglobin value was $9.3 \mathrm{gm} / \mathrm{dl}$. The ionized calcium level was maintained at $1.0 \mathrm{mmol} / \mathrm{L}$ before and after bypass, and boluses of calcium were given no closer than 15 minutes before measurements. All postbypass measurements were made before protamine was given. Patient 1 received dopamine $10 \mu \mathrm{g}^{-1} \cdot \mathrm{kg}^{-1} \cdot \mathrm{min}^{-1}$ before and after bypass. None of the other patients had any inotropic agents before or after the operation.

Assessment of left ventricular function. The conductance catheter has been extensively validated for left ventricular volume measurement. Details of the theory and practical application of the conductance catheter are presented elsewhere. ${ }^{6-11}$ Left ventricular function was assessed with the patient's chest and pericardium opened with ventilation stopped at end-expiration, immediately before the start of cardiopulmonary bypass, and then repeated at the end between 5 and 10 minutes after bypass. Real-time left ventricular pressure-volume loops were generated with the use of a conductance catheter and Mikro-Tip pressure catheter (2F) inserted through the left ventricular apex and secured with a pledget and purse-string suture. The conductance catheters were custom built (NuMed Inc., Hopkinton, N.Y.) single-field 3F (interelectrode distance 0.36 to $0.50 \mathrm{~cm}$ ) or $5 \mathrm{~F}$ (interelectrode distance $0.71 \mathrm{~cm}$ ) catheters with eight platinum ring electrodes. Conductance catheters of the appropriate size were selected on the basis of the measured left ventricular long axis from the parasternal long-axis view of the preoperative echocardiogram. The conductance catheter was manipulated until all five segmental volumes were in-phase and a counterclockwise rotating pressure-volume loop was formed, demonstrating that the conductance catheter was not in the left atrium or aorta and 
Table II. Perioperative changes in temperature, heart rate, blood resistivity (rho), and parallel conductance (Vc)

\begin{tabular}{|c|c|c|c|c|c|c|c|c|}
\hline \multirow[b]{2}{*}{ Patients } & \multicolumn{4}{|c|}{ Before bypass } & \multicolumn{4}{|c|}{ After bypass } \\
\hline & $\begin{array}{c}\text { Temp. } \\
\left({ }^{\circ} \mathrm{C}\right)\end{array}$ & $\begin{array}{c}\text { Heart } \\
\text { rate }\end{array}$ & $\begin{array}{c}\text { Rho } \\
(\Omega / \mathrm{cm})\end{array}$ & $\begin{array}{c}V c \\
(m l)\end{array}$ & $\begin{array}{c}\text { Temp. } \\
\left({ }^{\circ} \mathrm{C}\right)\end{array}$ & $\begin{array}{c}\text { Heart } \\
\text { rate }\end{array}$ & $\begin{array}{c}\text { Rho } \\
(\Omega / \mathrm{cm})\end{array}$ & $\begin{array}{c}V c \\
(m l)\end{array}$ \\
\hline 1 & 34.6 & 154 & 119 & 50.2 & 35.4 & 173 & 117 & 57.1 \\
\hline 2 & 34.2 & 146 & 150 & 47.8 & 37.2 & 157 & 123 & 52.4 \\
\hline 3 & 34.4 & 129 & 146 & 69.2 & 36.7 & 129 & 131 & 70.1 \\
\hline 4 & 35.5 & 135 & 140 & 114.5 & 37.1 & 138 & 146 & 142.9 \\
\hline 5 & 34.8 & 128 & 146 & 50.6 & 37.7 & 124 & 101 & 52.2 \\
\hline 6 & 34.2 & 107 & 127 & 40.0 & 35.0 & 121 & 111 & 34.6 \\
\hline 7 & 32.1 & 131 & 139 & 25.6 & 36.1 & 155 & 129 & 32.5 \\
\hline 8 & 35.5 & 128 & 142 & 24.7 & 36.7 & 140 & 131 & 30.9 \\
\hline 9 & 35.0 & 110 & 162 & 28.2 & 36.6 & 125 & 113 & 34.1 \\
\hline 10 & 34.6 & 109 & 148 & 29.2 & 31.6 & 125 & 112 & 60.5 \\
\hline 11 & 34.7 & 113 & 170 & 18.9 & 35.9 & 123 & 144 & 29.6 \\
\hline 12 & 34.5 & 103 & 157 & 26.0 & 35.1 & 100 & 136 & 44.8 \\
\hline 13 & 34.2 & 110 & 164 & 83.4 & 36.6 & 65 & 126 & 87.1 \\
\hline
\end{tabular}

therefore must lie within the long axis of the left ventricle. All volume measurements were corrected for blood resistivity and parallel conductance, and each of these was determined before and after bypass (Table II). Parallel conductance was determined by the hypertonic saline method $^{6}$ with the use of an injection of 0.5 to $2.5 \mathrm{ml}$ of $20 \%$ sodium chloride into the pulmonary artery. Preload was varied by transient (10 seconds) snaring of the inferior vena cava.

The conductance catheter signal encoding volume and electrocardiographic data was fed to a stimulator/processor unit (Sigma -5-DF, CardioDynamics International Corporation, San Diego, Calif.) and then to a committed microcomputer, where it was integrated with the amplified pressure signals (Fylde Isotransducer Amplifier) in custom-designed software.

Data analysis. From left ventricular pressure-volume loops generated under varying preloads, the end-systolic pressure-volume relationship, stroke work-end-diastolic volume relationship (preload-recruitable stroke work), and end-diastolic pressure-volume relationship were derived. Ventricular volumes tend to increase more than ventricular pressures with increasing body size. Indexation of end-systolic elastance (Ees) in human beings by body surface area does not decrease the between-subjects variance, ${ }^{12}$ and inasmuch as end-systolic volume is a linear function of body and heart weight, ${ }^{13}$ both the end-systolic (Ees) and end-diastolic elastance (Eed) measurements were indexed to body weight, to allow group analysis of data from children of greatly differing sizes. ${ }^{12}$ The slope of the stroke work-end-diastolic volume relationship $\left(\mathrm{M}_{\mathrm{w}}\right)$ is relatively independent of chamber size and was not indexed to body weight. ${ }^{14}$ The end-diastolic pressurevolume relationship was fitted with a straight line and by an exponential relationship of the form $\mathrm{P}_{\mathrm{ed}}=\mathrm{A}+$ $B_{\text {exp }}\left(k_{\text {ed }}\right)$, where $P_{\text {ed }}$ and $V_{\text {ed }}$ are the end-diastolic pressure and volume, respectively, and $\mathrm{A}, \mathrm{B}$, and $\mathrm{k}$ are constants. Load-dependent indices were also obtained from steady-state pressure-volume loops: tau $(\tau)$, the time constant of isovolumic relaxation; $\mathrm{dp} / \mathrm{dt}_{\max }$ and $\mathrm{dp} / \mathrm{dt}_{\text {min }}$. $\mathrm{Dp} / \mathrm{dt}_{\max }$ and $\mathrm{dp} / \mathrm{dt}_{\min }$ were normalized by dividing by the maximal developed pressure $\left(\mathrm{P}_{\max }\right)$ and the end-systolic pressure $\left(\mathrm{P}_{\mathrm{es}}\right)$, respectively, to give $\left(\mathrm{dp} / \mathrm{dt}_{\max }\right) / \mathrm{P}_{\max }$ and $\left(\mathrm{dp} / \mathrm{dt}_{\min }\right) / \mathrm{P}_{\mathrm{es}}{ }^{15}$ Each patient acted as his or her own control, and preoperative and postoperative values for the indices of left ventricular function were compared by means of a paired $t$ test. The null hypothesis was rejected if $p<0.05$. Results are presented as mean \pm standard deviation.

\section{Results}

Except for patient 1, all patients were extubated within a few hours of the operation. Patient 1 was known to have a severely hypoplastic lung with pulmonary hypertension and continued to receive ventilatory support until treatment was withdrawn on the eighth postoperative day. There was no difference in clinical course between the three patients (all with secundum atrial septal defects) in whom technically adequate recordings could not be achieved and the remaining 13 patients used for analysis. During the course of the past 2 years our catheter specifications have changed to a stiffer catheter with a reinforced core that diminishes catheter whip (conformational and spatial change during the cardiac cycle), although the catheter remains flexible enough to use in a small heart. Catheter whip leads to artifactual changes in ventricular volume and bizarre loop patterns, for example, a figure of eight. It is essential to measure the echocardiographic left ventricular long axis to ensure that a catheter with appropriate total interelectrode distance is selected, which helps to ensure that if the catheter is not in the left atrium or aorta (from the phase of the segmental volumes and direction of rotation of the pressure-volume loops) it will lie 

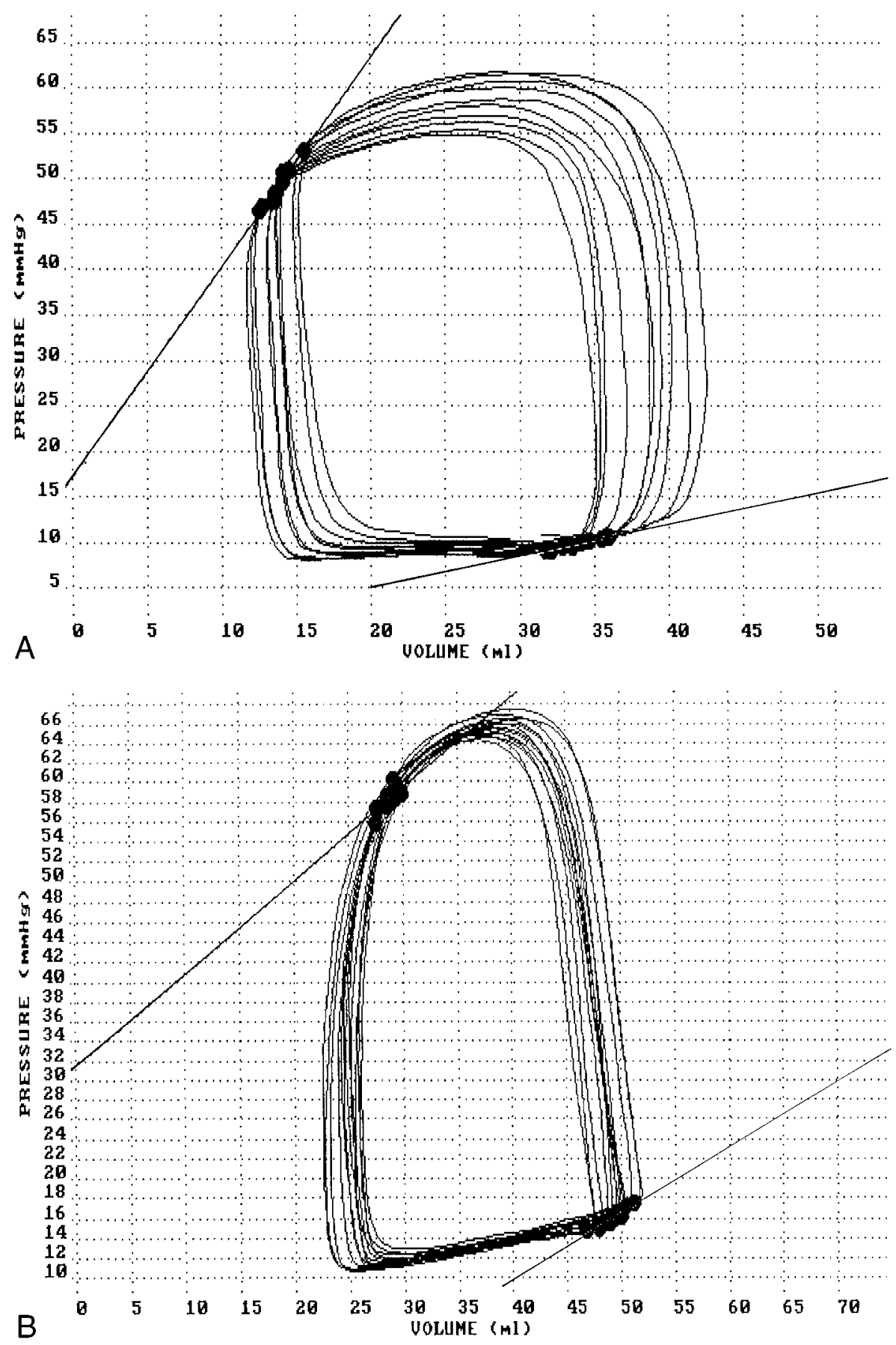

Fig. 1. Left ventricular pressure-volume loops while the inferior vena cava is being snared, showing a decrease in Ees from $2.30 \mathrm{~mm} \mathrm{Hg} / \mathrm{ml}$ before bypass (A) to $0.93 \mathrm{~mm} \mathrm{Hg} / \mathrm{ml}$ after bypass (B).

approximately along the whole of the left ventricular long axis.

For the group overall, postbypass heart rate and temperature had increased $4.1 \%$ and $4.8 \%$, respectively. Fig. 1 demonstrates a representative family of left ventricular pressure-volume loops generated by snaring of the inferior vena cava before (Fig. 1, $A$ ) and after the operation (Fig. 1, B). The end-systolic pressure-volume relationship determinations had a mean $R^{2}=0.78$ (mean of $13 \times 2$ regressions) and the end-diastolic pressure-volume relationship regressions had a mean $R^{2}=0.81$ (mean of $8 \times 2$ 
Table III. Perioperative changes in left ventricular function

\begin{tabular}{|c|c|c|c|}
\hline & Before bypass & After bypass & $\begin{array}{c}\text { Relative change } \\
(\%)\end{array}$ \\
\hline $\begin{array}{l}\text { Ees } \\
\left(\mathrm{mm} \mathrm{Hg} \cdot \mathrm{ml}^{-1} \cdot \mathrm{kg}^{-1}\right)\end{array}$ & $0.34 \pm 0.17$ & $0.21 \pm 0.15$ & $\begin{array}{l}-40.7 \\
\quad(p<0.001)\end{array}$ \\
\hline $\begin{array}{l}\text { Eed } \\
\left(\mathrm{mm} \mathrm{Hg} \cdot \mathrm{ml}^{-1} \cdot \mathrm{kg}^{-1}\right)\end{array}$ & $0.06 \pm 0.11$ & $0.10 \pm 0.19$ & $\begin{array}{l}78.3 \\
(p=0.57)\end{array}$ \\
\hline $\begin{array}{l}\mathrm{M}_{\mathrm{w}} \\
\left(\mathrm{mm} \mathrm{Hg} \cdot \mathrm{ml}^{-1}\right)\end{array}$ & $76.38 \pm 49.57$ & $67.40 \pm 39.23$ & $\begin{array}{l}-11.1 \\
\quad(p=0.75)\end{array}$ \\
\hline $\begin{array}{l}\left(\mathrm{dp} / \mathrm{dt}_{\max }\right) / \mathrm{P}_{\max } \\
\left(\mathrm{sec}^{-1}\right)\end{array}$ & $8.35 \pm 1.42$ & $8.99 \pm 1.29$ & $\begin{array}{l}7.7 \\
(p=0.17)\end{array}$ \\
\hline $\begin{array}{l}\left(\mathrm{dp} / \mathrm{dt}_{\min }\right) / \mathrm{P}_{\mathrm{es}} \\
\left(\mathrm{sec}^{-1}\right)\end{array}$ & $11.75 \pm 3.19$ & $10.92 \pm 2.4$ & $\begin{array}{l}-7.1 \\
(p=0.24)\end{array}$ \\
\hline $\begin{array}{l}\tau \\
\left(\sec ^{-1}\right)\end{array}$ & $45.8 \pm 18.6$ & $44.3 \pm 12.8$ & $\begin{array}{l}-3.3 \\
(p=0.76)\end{array}$ \\
\hline
\end{tabular}

Ees, End-systolic elastance; Eed, end-diastolic elastance; $M_{w}$ slope of the stroke work-end-diastolic volume relationship; $\left(d p / d t_{\max }\right) / P_{\max }$ maximal value of time derivative of left ventricular pressure normalized by maximal developed pressure; $\left(d p / d t_{\min }\right) / P_{e s}$, minimal value of time derivative of left ventricular pressure normalized by end-systolic pressure; $\tau$, time constant of isovolumic relaxation.

regressions; five patients were excluded because either their prebypass or postbypass determinations had $r \leq 0.7)$. For the group as a whole, Ees decreased by $40.7 \%$ from $0.34 \pm 0.17$ to $0.21 \pm 0.15$ $\mathrm{mm} \mathrm{Hg} \mathrm{ml}{ }^{-1} \mathrm{~kg}^{-1}\left(p<0.001, n=13\right.$, mean $R^{2}=$ $0.78)$. The end-diastolic pressure-volume relationship was adequately represented by a straight line (mean $r^{2}=0.81$ ) and there was no significant change in Eed (Table III). With an exponential description there was no improvement in the overall closeness of fit (mean $r^{2}=0.81$ ), and again there was no significant change in the end-diastolic pressure-volume relationship before and after bypass (prebypass $\mathrm{A}=-43.1 \pm 74.8$, postbypass $\mathrm{A}=$ $-1.67 \pm 22.5, p=0.20$; prebypass $\mathrm{B}=44.7 \pm 72.5$, postbypass $\mathrm{B}=7.8 \pm 19.6, p=0.23$; prebypass $\mathrm{k}=$ $0.21 \pm 0.46$, postbypass $\mathrm{k}=0.28 \pm 0.39, p=0.79$ ). There was no significant change before and after bypass in $\mathrm{M}_{\mathrm{w}}$ (prebypass $=67.40 \pm 39.23 \mathrm{~mm} \mathrm{Hg}$ $\mathrm{ml}^{-1}$, postbypass $=76.38 \pm 49.57 \mathrm{~mm} \mathrm{Hg} \mathrm{ml}^{-1}, p=$ $0.75)$. There was essentially no change in $\left(\mathrm{dp} / \mathrm{dt}_{\max }\right) /$ $\mathrm{P}_{\text {max }}(p=0.17),\left(\mathrm{dp} / \mathrm{dt}_{\min }\right) / \mathrm{P}_{\mathrm{es}}(p=0.24)$, and $\tau(p=$ $0.76)$. There was no relationship between perioperative deterioration in the indices of ventricular function and cardiopulmonary bypass time, aortic crossclamp time, type of cardioplegia, and age.

\section{Discussion}

Although extensive animal literature is available on the effects of global ischemia and cardiopulmonary bypass on left ventricular function, there are substantial interspecies differences, and the relevance of these studies to the immature human heart with structural defects is questionable. ${ }^{16}$ Previous clinical pediatric studies have suggested incomplete myocardial protection based on the depletion of adenosine triphosphate ${ }^{2,3}$ and evidence of free radical generation and histologic damage $e^{4,5}$ in myocardial biopsy specimens. Attempts to assess ventricular function were forced to infer this indirectly, by demonstrating low cardiac output ${ }^{17-20}$ or an obtunded increment in cardiac output in response to volume. ${ }^{21}$ More recently in adult patients, loadindependent indices of left ventricular function have been derived from pressure-volume loops ${ }^{22,23}$ or analogous indices from pressure-area loops, ${ }^{24}$ allowing direct quantitation of impaired systolic and diastolic chamber function. To our knowledge this is the first attempt to quantitate perioperative loadindependent indices of left ventricular function in children undergoing cardiac operations. Our intention is not to suggest that routine atrial septal defect closure results in clinically significant left ventricular dysfunction in the perioperative period, but rather to present a technique that can detect even mild ventricular dysfunction.

A significant $38.2 \%$ decrease in Ees was noted, reflecting a deterioration in systolic function in this study. It is reassuring that this degree of change in systolic function has also been found in adult studies in which different methods were used ${ }^{15,22-26}$ and that our data for Eed and normalized values for $\mathrm{dp} / \mathrm{dt}_{\max }$ and $\mathrm{dp} / \mathrm{dt}_{\min }$ are similar to previously published values. ${ }^{15,22,23}$ The absence of a significant change in Eed is attributable to our study design, in which all measurements were made in the presence of an open chest and a widely open pericardium, thus diminishing the magnitude of change in the end-diastolic pressure-volume relationship, but allowing better evaluation of the true myocardial end-diastolic pressure-volume relationship. The absence of a statistically significant change in preload- 
recruitable stroke work, we believe, is due to the known decreased sensitivity of this index in comparison with Ees in detecting changes in contractility. ${ }^{27}$ For example, in a study in anesthetized dogs with a lateral thoracotomy and open pericardium, a dopamine concentration of $6 \mu \mathrm{g} / \mathrm{kg}$ per minute increased Ees $80 \%$ whereas the $M_{w}$ increased only $26 \% .{ }^{27}$ In our study Ees decreased by $38.2 \%$ and $\mathrm{M}_{\mathrm{w}}$ decreased by $11.1 \%$, suggesting a proportionate change in both indices. These observations are consistent with clinical experience that this degree of change in these indices reflects only mild deterioration in ventricular function. Load-dependent indices of ventricular function used in this study $\left(\mathrm{dp} / \mathrm{dt}_{\max }, \mathrm{dp} / \mathrm{dt}_{\min }\right.$, and $\tau$ ) measure rates of pressure change, albeit during different phases of the cardiac cycle. Pressure is measured extremely accurately by current Mikro-Tip pressure catheters, and the absence of a statistically significant perioperative change in any of these indices demonstrates their dependence on loading conditions, which in this clinical situation vary dramatically between time points and patients. Clearly with more extreme myocardial injury, the dominant influence on these indices may become cardiomyocyte performance rather than loading conditions, but this again emphasizes their lack of sensitivity as functional indices.

Some methodologic considerations regarding the application of this technique are worthy of comment. The apical approach for conductance catheter insertion has been validated in an animal model, ${ }^{9-11}$ and our group has validated left ventricular parallel conductance measurement in the perioperative period for infants and children with intact ventricular septum and for those with ventricular septal defects. ${ }^{28}$ The quality of the recordings and ventricular function data can be striking in good studies. Nonetheless, in our initial experience in these patients and others with more complex lesions, we found it was not possible to obtain technically adequate recordings in about $15 \%$ to $20 \%$ of cases. With a stiffer catheter our failure rate approaches $10 \%$, with the major current limitation on achieving good recordings being patient instability. However, at present, combined use of conductance catheters and micromanometers in the perioperative setting remain research rather than clinical tools. As with other animal and clinical studies, alpha, the dimensionless gain constant relating conductance-derived volumes to a reference method, was assumed to be unity. ${ }^{6-10}$ Although not measured in this study, we believe alpha would have remained relatively con- stant between measurements as the conductance catheter lay along the left ventricular long axis on both occasions. By using a catheter with total interelectrode distance similar to the left ventricular long axis, we ensured that if all the segments were in phase the catheter would lie along the long axis. Once a satisfactory position was found, the catheter was firmly tethered at the left ventricular apex. Care was taken to ensure minimal handling of the left ventricle, and this was rendered easier by all operations not requiring ventricular surgery. Clearly for more complex hearts it would be preferable to measure alpha, particularly when large changes in ventricular size and geometry may be anticipated (e.g., with an intraoperative flow probe, before and after a Fontan operation).

Although it is appreciated that the conductance technique has its own deficiencies, relatively few alternatives are available for clinical studies in small children. Two-dimensional echocardiography allows excellent qualitative assessment of ventricular function, which suffices for clinical purposes. However, quantitative measurements from pressure-area loops or wall stress analysis all entail geometric assumptions that are particularly suspect in congenital heart disease. In addition, echocardiographic planimetry can be extremely difficult in malformed hearts with complex chamber geometry, hypertrophy, or incoordinate contraction, which is prominent in the reperfusion and postoperative periods. ${ }^{15,29} \mathrm{It}$ has previously been shown in this situation that $\mathrm{M}$-mode-derived indices of ventricular function are critically dependent on the echo plane used. ${ }^{30}$ Tissue marking by ultrasonic crystals for dimension measurement is limited to use with the chest open, and crystals allow dimension measurement in only one or a limited number of chords, again making them vulnerable to incoordinate contractions. Conductance catheter techniques overcome these geometric considerations by measuring chamber volume as the time-varying conductance because of the time-varying blood pool contained within that chamber. However, the current apical approach for conductance catheter placement is also limited to use with an open chest. In conclusion, we have demonstrated that mild ventricular dysfunction can be quantified by load-independent indices derived from left ventricular pressure-volume analysis, using a conductance catheter and Mikro-Tip pressure catheter. Even in these brief operations, which represent the simplest model of pediatric cardiac surgery, there is evidence of incomplete myocardial protec- 
tion. This technique has the potential to refine our assessment of clinically significant ventricular dysfunction after more complex cardiac operations and guide the development of improved strategies of myocardial protection.

Many thanks to R. S. Szwarc for providing analytical software.

\section{REFERENCES}

1. Bull C, Cooper J, Stark J. Cardioplegic protection of the child's heart. J Thorac Cardiovasc Surg 1984;88:287-91.

2. Hammon JW, Graham TP, Boucek RJ, Parrish MD, Merrill WH, Bender HW. Myocardial adenosine triphosphate content as a measure of metabolic and functional myocardial protection in children undergoing cardiac operation. Ann Thorac Surg 1987;44:467-70.

3. Lofland GF, Abd-Elfattah AS, Wyse R, de Leval M, Stark J, Wechsler AS. Myocardial adenine nucleotide metabolism in pediatric patients during hypothermic cardioplegic arrest and normothermic ischemia. Ann Thorac Surg 1989;47:663-8.

4. Sawa Y, Matsuda H, Shimazaki Y, Hirose H, Kadoba K, Takami $\mathrm{H}$, et al. Ultrastructural assessment of the infant myocardium receiving crystalloid cardioplegia. Circulation 1987;76(Suppl):V141-5.

5. del Nido P, Mickle DAG, Wilson GJ, Benson LN, Coles JG, Trusler GA, et al. Evidence of myocardial free radical injury during elective repair of tetralogy of Fallot. Circulation 1987;76(Suppl):V174-9.

6. Baan J, van der Velde ET, de Bruin HG, Smeenk GI, Koops $\mathrm{J}$, van Dijk $\mathrm{AD}$, et al. Continuous measurement of left ventricular volume in animals and humans by conductance catheter. Circulation 1984;70:812-23.

7. Kass DA, Yamazaki T, Burkhoff D, Maughan WL, Sagawa K. Determination of left ventricular end-systolic pressure-volume relationships by the conductance (volume) catheter technique. Circulation 1986;73:586-95.

8. Cassidy SC, Teitel DF. The conductance volume catheter technique for measurement of left ventricular volume in young piglets. Pediatr Res 1992;31:85-90.

9. Hidetsugu A, Ishizaka S, Kameyama T, Nozawa T, Miyagi K, Sasayama S. Serial reproducibility of conductance catheter volumetry of left ventricle in conscious dogs. Am J Physiol 1992;262:H911-5

10. Ishizaka $\mathrm{S}$, Asanoi $\mathrm{H}$, Wada $\mathrm{O}$, Kameyama $\mathrm{T}$, Inoue $\mathrm{H}$. Loading sequence plays an important role in enhanced load sensitivity of left ventricular relaxation in conscious dogs with tachycardia-induced cardiomyopathy. Circulation 1995;92: 3560-7.

11. Ito H, Takaki M, Yamaguchi H, Tachibana H, Suga H. Left ventricular volumetric conductance catheter for rats. Am J Physiol 1996;270:H1509-14.

12. Belcher P, Boerboom LE, Olinger GN. Standardization of end-systolic pressure-volume relation in the dog. Am J Physiol 1985;249:H547-53.

13. Holt JP, Rhode EA, Kines H. Ventricular volumes and body weight in mammals. Am J Physiol 1968;215:704-15.

14. Kass DA. Myocardial mechanics. In: Poole-Wilson PA, Colucci WS, Massie BM, Chatterjee K, Coats AJS, editors. Heart failure. New York: Churchill Livingstone; 1997. p. 87-108. 15. Jin XY, Gibson DG, Pepper JR. Early changes in regional and global left ventricular function after aortic valve replacement: comparison of crystalloid, cold blood, and warm blood cardioplegias. Circulation 1995;92(Suppl):II155-62.

16. Baker JE, Boerboom LE, Olinger GN. Is protection of ischemic neonatal myocardium by cardioplegia species dependent? J Thorac Cardiovasc Surg 1990;99:280-7.

17. Parr GVS, Blackstone EH, Kirklin JW. Cardiac performance and mortality early after intracardiac surgery in infants and children. Circulation 1975;51:867-74.

18. Keagy BA, Wilcox BR, Lucas CL, Hsiao HS, Henry GW, Baudino M, Bornzin G. Constant postoperative monitoring of cardiac output after correction of congenital heart defects. J Thorac Cardiovasc Surg 1987;93:658-64.

19. Chang AC, Kulik TJ, Hickey PR, Wessel DL. Real-time gas-exchange measurement of oxygen consumption in neonates and infants after cardiac surgery. Crit Care Med 1993;21:1369-75.

20. Wernovsky G, Wypij D, Jonas RA, Mayer JE, Hanley FL, Hickey PR, et al. Postoperative course and hemodynamic profile after the arterial switch operation in neonates and infants: a comparison of low-flow cardiopulmonary bypass and circulatory arrest. Circulation 1995;92:2226-35.

21. Burrows FA, Williams WG, Teoh KH, Wood AE, Burns J, Edmonds J, et al. Myocardial performance after repair of congenital cardiac defects in infants and children: response to volume loading. J Thorac Cardiovasc Surg 1988;96:548-56.

22. Schreuder JJ, Biervielet JD, van der Velde ET, ten Have K, van Dijk AD, Meyne NG, et al. Systolic and diastolic pressure-volume relationships during cardiac surgery. J Cardiothorac Vasc Anaesth 1991;5:539-45.

23. De Hert SG, Rodrigus IE, Haenen LR, De Mulder PA, Gillebert TC. Recovery of systolic and diastolic left ventricular function early after cardiopulmonary bypass. Anesthesiology 1996;85:1063-75

24. Gorcsan J, Gasior TA, Mandarino WA, Deneault LG, Hattler BG, Pinsky MR. Assessment of the immediate effects of cardiopulmonary bypass on left ventricular performance by on-line pressure-area relations. Circulation 1994;89:180-90.

25. Mangano DT. Biventricular function after myocardial revascularization in humans: deterioration and recovery patterns during the first 24 hours. Anesthesiology 1985;62:571-7.

26. Breisblatt WM, Stein K, Wolfe CJ, Follansbee WP, Capozzi $\mathrm{J}$, Armitage JM, et al. Acute myocardial dysfunction and recovery: a common occurrence after coronary bypass surgery. J Am Coll Cardiol 1990;15:1261-9.

27. Little WC, Cheng CP, Mumma M, Igarishi Y, VintenJohansen J, Johnston WE. Comparison of measures of left ventricular contractile performance derived from pressurevolume loops in conscious dogs. Circulation 1989;80:1378-7.

28. White PA, Chaturvedi RR, Shore DS, Lincoln C, Bishop AJ, Oldershaw PJ, et al. Does left ventricular parallel conductance change during the cardiac cycle? Observations in infants and children with congenital heart disease. Am J Physiol. In press.

29. Rynning SE, Birkeland S, Hexeberg E, Grong K. Changes in myocardial contraction pattern during initial reperfusion. Am J Physiol 1994;266:H980-6.

30. Martins TC, Rigby ML, Redington AN. Left ventricular performance in children: transthoracic versus transoesophageal measurement of M-mode derived indices. Br Heart J 1992;68:485-7. 